\title{
X-ray Photoelectron Spectroscopic Study on the Anodic Passivity of Sputterdeposited W-Ta Alloys in $12 \mathrm{M} \mathrm{HCl}$
}

\author{
Jagadeesh Bhattarai \\ Central Department of Chemistry, Tribhuvan University, Kirtipur, Kathmandu \\ e-mail:bhattarai05@yahoo.com
}

\begin{abstract}
The role of a simultaneous additions of tungsten and tantalum on the anodic passivity of the passive films of the sputter-deposited nanocrystalline W-xTa alloys was studied using immersion tests, electrochemical measurements and X-ray photoelectron spectroscopic (XPS) analysis. The formation of spontaneous passive film on the alloys, which is composed of double oxyhydroxide of tungsten and tantalum ions are responsible for their higher corrosion resistance than those of the alloy-constituting elements in $12 \mathrm{M} \mathrm{HCl}$ solution open to air at $30^{\circ} \mathrm{C}$. The quantitative surface analysis by XPS is clarified that the improved anodic passivity of the alloys than those of alloy-constituting elements is based on the formation of new anodic passive oxyhydroxide films composed of $\mathrm{W}^{6+}$ and $\mathrm{Ta}^{5+}$ ions. These films have higher protectiveness and stability than those of passive oxyhydroxide films of alloy-constituting elements, that is, oxyhydroxides of hexavalent tungsten and pentavalent tantalum after potentiostatic polarization for $1 \mathrm{~h}$ in $12 \mathrm{M} \mathrm{HCl}$.
\end{abstract}

Key words: W-Ta alloys, sputter deposition, polarization curve, passivity, XPS surface analysis

\section{Introduction}

The formation of anodic passive films formed on the metals or alloys has gained great scientific interest for a long time. It is important from a practical point of view that the anodic film causes the passivity. The passivity of metals or alloys mostly concerns the corrosion resistance and hence the interest is focused on the chemical stability of the anodic passive films. On the other hand, the breakdown of the anodic passive films has been the subject of many investigations. The pitting corrosion is one of the most common and dangerous types of localized corrosion of the anodic films. Therefore, the immunity to pitting corrosion is one of the most interesting characteristics of the passivity of the metals or alloys.
The passivating elements such as tungsten and tantalum can improve corrosion resistance as well as the localized corrosion like pitting corrosion of alloys. The properties of the anodic passive films formed on tungsten metal had reported. Di Quarto et al. (1983) have been stated that the anodic film formed on tungsten showed a duplex structure consisting of an inner amorphous barrier-type anodic $\mathrm{WO}_{3}$ film and outer porous crystalline layer. On the other hand, an insulating layer of $\mathrm{WO}_{3}$ was formed by anodic polarization of tungsten in acidic environments (Johnson and Wu 1971). Several surface studies have been carried out for an understanding of the role of the tungsten in the passivation mechanisms of stainless steels in aggressive chloride media (Naka et 
al. 1978; Bui et al. 1983; Wang and Merz 1984; Habazaki et al. $1991 \mathrm{a}, 1991 \mathrm{~b})$.

On the other hand, tantalum is widely known for its superior corrosion resistance in aggressive acidic media. Amorphous nickel-base alloys containing certain amounts of tantalum exhibit very high corrosion resistant in boiling acids (Kawashima et al. 1985). Lee et al. $(1996,1997)$ reported a beneficial effect of tantalum to improve the corrosion resistance of nickel-base alloys in $12 \mathrm{M} \mathrm{HCl}$. A series of the sputterdeposited binary tantalum-containing alloys showed higher corrosion resistance than those of alloying elements due to spontaneous passivation in aggressive media (Shaw et al. 1991, Yoshioka et al. 1991, 1994, Kim et al. 1994, Park et al. 1996, Hashimoto et al. 1996, ElMoneim et al. 1997; Bhattarai et al. 1998 a).

It has been reported that the high corrosion resistance of the sputter-deposited binary and ternary tungstenbased alloys in $12 \mathrm{M} \mathrm{HCl}$ was based on the formation of new passive double oxyhydroxide films of tetravalent tungsten and alloy-constituting cations (Bhattarai 1998, 2010, 2011 a, 2011 b; Bhattarai et al. 1995, 1997, 1998 a, 1998 b, 1998 c). The tetravalent tungsten was the main oxidation state of tungsten for these tungsten-based binary alloys at $+0.2 \mathrm{~V}$ (SCE) or lower potentials, while the hexavalent tungsten is the main oxidation state of tungsten at $+0.4 \mathrm{~V}$ (SCE) or higher potentials in hydrochloric acid solutions. According to Habazaki et al. (1992), the passive film on tungsten was tetravalent tungsten oxyhydroxide and hexavalent tungsten oxyhydroxide was not the true passive film. However, the transpassivation of tungsten is clearly different from those of chromium and molybdenum. Transpassivation of chromium and molybdenum was resulted in sharp increases in the anodic current density in $12 \mathrm{M} \mathrm{HCl}$ solution (Kim et al. 1994, Park et al. 1996, Hashimoto 2007). By contrast, the present author has been reported in polarization curves of tungsten and tungsten-based binary alloys that the oxidation from the tetravalent state to the hexavalent state of tungsten did not lead to the transpassivation, although the anodic current density was significantly high. In this context, it is necessary and interesting to study the potential dependence of the surface composition of the anodic passive films formed on the sputter-deposited W-xTa alloys to clarify the mechanisms of the anodic passivity of the binary alloys in hydrochloric acids.
The main objectives of the present study are to characterize the surface composition and structure of the anodic passive films formed on the sputterdeposited binary W-xTa (x = 23 and 60 at\%) alloys after potentiostatic polarization for $1 \mathrm{~h}$ in $12 \mathrm{M} \mathrm{HCl}$ solution open to air at $30^{\circ} \mathrm{C}$ using electrochemical measurements and $\mathrm{X}$-ray photoelectron spectroscopic (XPS) analyses.

\section{Methodology}

The $\mathrm{W}-\mathrm{xTa}(\mathrm{x}=23,60$ and 77 at\%) alloys were prepared using direct current (DC) magnetron sputtering on glass substrate as described elsewhere (Bhattarai 1995, 1998). The structure of the sputter-deposited W-xTa alloys used in the present study was confirmed as nanocrystalline single phase solid solution from $\mathrm{X}-$ ray diffraction patterns having the apparent grain size ranges from 8-18 nm (Bhattarai 1998; Bhattarai et al. 1998a).

Prior to immersion tests, electrochemical measurements and XPS analyses, the surfaces of the alloy specimens were mechanically polished with a silicon carbide paper up to grit number 1500 in cyclohexane, rinsed by acetone and dried in air. The average corrosion rate of the alloys was estimated from the weight loss after immersion for $168 \mathrm{~h}$ in $12 \mathrm{M} \mathrm{HCl}$ solution open to air at $30^{\circ} \mathrm{C}$. Open circuit immersion and potentiostatic polarization at several potential values for $1 \mathrm{~h}$ in $12 \mathrm{M}$ $\mathrm{HCl}$ solution were carried out. A platinum mesh and a saturated calomel electrode (SCE) were used as counter and reference electrodes, respectively. All the potentials given in this paper are relative to SCE.

Before and after open circuit immersion or potentiostatic polarization, composition of the surface films formed on the alloy specimens was analyzed using XPS (Shimadzu ESCA-850 photoelectron spectrometer). The XPS spectra over a wide binding energy region (0-1000 eV) were exhibited peaks of chlorine, carbon, oxygen, tungsten and tantalum. The integrated intensities of the $\mathrm{C} 1 \mathrm{~s}, \mathrm{O} 1 \mathrm{~s}, \mathrm{~W} 4 \mathrm{f}$ and Ta $4 \mathrm{f}$ spectra were separately obtained for the quantitative surface analysis as described elsewhere (Bhattarai 1998). For the specimen polarized or immersed in $12 \mathrm{M}$ $\mathrm{HCl}$ solution, the $\mathrm{Cl} 2 \mathrm{p}$ spectrum was detected at about $199 \mathrm{eV}$, which comes from chloride ions. However, the intensity of the $\mathrm{Cl} 2$ p peak was very low and hence the concentration of chloride ions was not considered in 
the calculation. The binding energies of the electrons were calibrated using the method described elsewhere (Asami 1976; Asami and Hashimoto 1977). The peak binding energies of each peak were further corrected using the energy value of $285 \mathrm{eV}$ for $\mathrm{C} 1$ s electron state. The composition and thickness of anodic passive films and the composition of the underlying alloy surface were quantitatively determined by a previously proposed method (Asami 1976) using integrated intensities of photoelectrons under the assumption of a three layer model of the outermost contaminant hydrocarbon layer of uniform thickness, the surface film of uniform thickness and the underlying alloy surface of $\mathrm{X}$-ray photoelectron spectroscopically infinite thickness. The photoionization cross-section of the $\mathrm{W} 4 \mathrm{f}$ and Ta $4 \mathrm{f}$ electrons relative to the $\mathrm{O} 1 \mathrm{~s}$ electrons used were 2.97 (Kawashima et al. 1984) and 2.617 (Kim et al. 1994), respectively.

\section{Results and Discussion \\ Corrosion behavior and passivity of $\mathrm{W}-\mathrm{xTa}$ alloys}

The corrosion rates of the sputter-deposited $\mathrm{W}-\mathrm{Ta}$ alloys and alloy-constituting elements were estimated from weight losses after immersion in $12 \mathrm{M} \mathrm{HCl}$ solution. The weight loss for each specimen was estimated two to three times and the average corrosion rate was calculated. Figure 1 shows the average corrosion rates of the $\mathrm{W}-23 \mathrm{Ta}, \mathrm{W}-60 \mathrm{Ta}$ and $\mathrm{W}-77 \mathrm{Ta}$ alloys after immersion for $168 \mathrm{~h}$ in $12 \mathrm{M} \mathrm{HCl}$ solution at $30^{\circ} \mathrm{C}$. The corrosion rates of the sputter-deposited tungsten and tantalum are also shown for comparison. The W-60Ta and W-77Ta alloys showed more than two orders of magnitude lower rate than that of sputter-deposited tungsten and even lower than that of sputter-deposited tantalum metal. However, the corrosion rate of the $\mathrm{W}-23 \mathrm{Ta}$ alloy shows almost same corrosion rate of the tantalum. This result clearly revealed that the corrosion resistance of the $\mathrm{W}-\mathrm{xTa}$ alloys is surprisingly improved in $12 \mathrm{M} \mathrm{HCl}$ at $30^{\circ} \mathrm{C}$. Consequently, it can be said that both tungsten and tantalum improve the corrosion resistance of the $\mathrm{W}-$ xTa alloys synergistically.

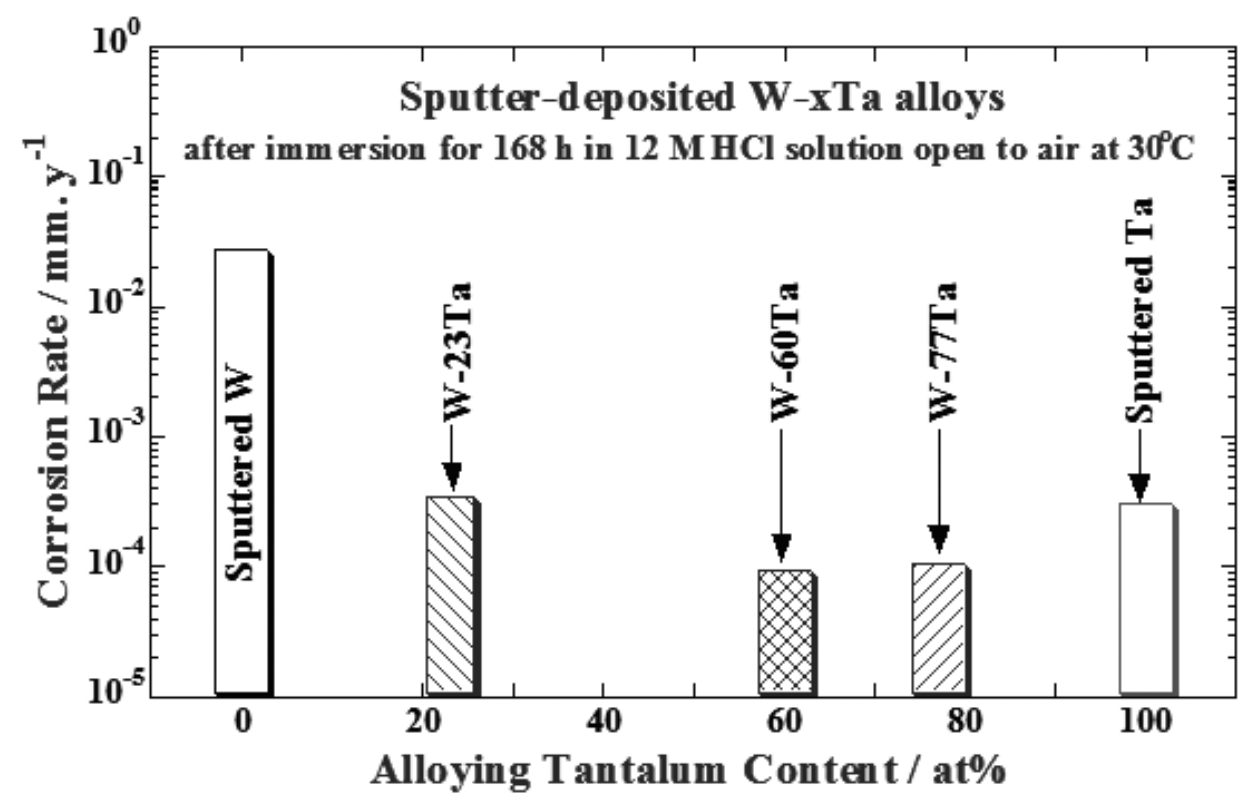

Fig.1. Corrosion rates of the sputter-deposited W-xTa alloys including tungsten and tantalum after immersion for $168 \mathrm{~h}$ in $12 \mathrm{M} \mathrm{HCl}$ solution open to air at $30^{\circ} \mathrm{C}$. 
Potentiostatic polarization measurements were carried out for the $\mathrm{W}-\mathrm{xTa}$ alloys to gain a better understanding of the anodic passivity of the alloys after potentiostatic polarization for $1 \mathrm{~h}$ in $12 \mathrm{M} \mathrm{HCl}$. Figure 2 shows the changes in anodic current densities of the W-23Ta and W-60Ta alloys as a function of polarization time. The anodic current densities of the alloys at all potentials are decreased with polarization time. According, the protective quality of the anodic passive films formed on the sputter-deposited $\mathrm{W}-$ xTa alloys increased with polarization time in $12 \mathrm{M}$ $\mathrm{HCl}$ solution.
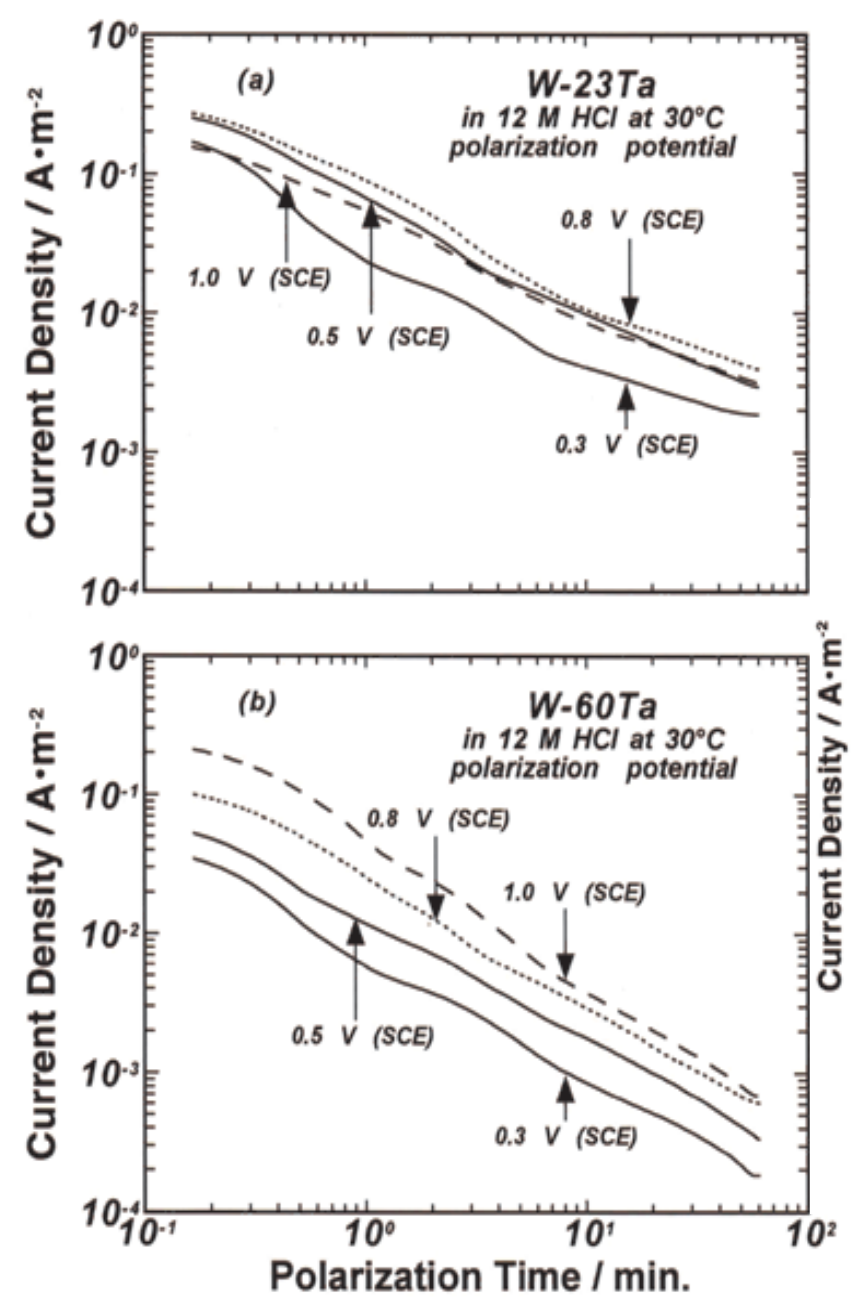

Fig.2. The change in the anodic current density with polarization time for the sputter-deposited (a) W-23Ta and (b) W-60Ta alloys after potentiostatic polarization for $1 \mathrm{~h}$ in $12 \mathrm{M} \mathrm{HCl}$ solution open to air at $30^{\circ} \mathrm{C}$.
Figure 3 shows the potentiostatic anodic and cathodic polarization curves of the sputter-deposited $\mathrm{W}-23 \mathrm{Ta}$ and W-60Ta alloys including the sputter-deposited tantalum metal after potentiostatic polarization at different potentials for $1 \mathrm{~h}$ in $12 \mathrm{M} \mathrm{HCl}$ solution open to air at $30^{\circ} \mathrm{C}$. Spontaneous passivation occurs for both the examined $\mathrm{W}-\mathrm{Ta}$ alloys as well as tantalum metal. The open circuit potentials of the alloys are shifted to more positive direction than that of the sputter-deposited tantalum. The anodic current density of the alloys is decreased with increasing the tantalum content in the $\mathrm{W}-\mathrm{xTa}$ alloys in $12 \mathrm{M} \mathrm{HCl}$, indicating that the protectiveness of the anodic passive films formed on the $\mathrm{W}$-Ta alloys is better than that of tungsten metal. Furthermore, it is meaningful to mention here that the $\mathrm{W}-60 \mathrm{Ta}$ alloy showed lowest anodic current density which is even lower that that of the sputter-deposited tantalum metal. Therefore, the $\mathrm{W}$-xTa alloys containing adequate amount of tungsten showed the most stable passivity in the anodic potential region. These facts are in agreement with higher corrosion resistance than those of alloyconstituting elements as shown in Fig.1.

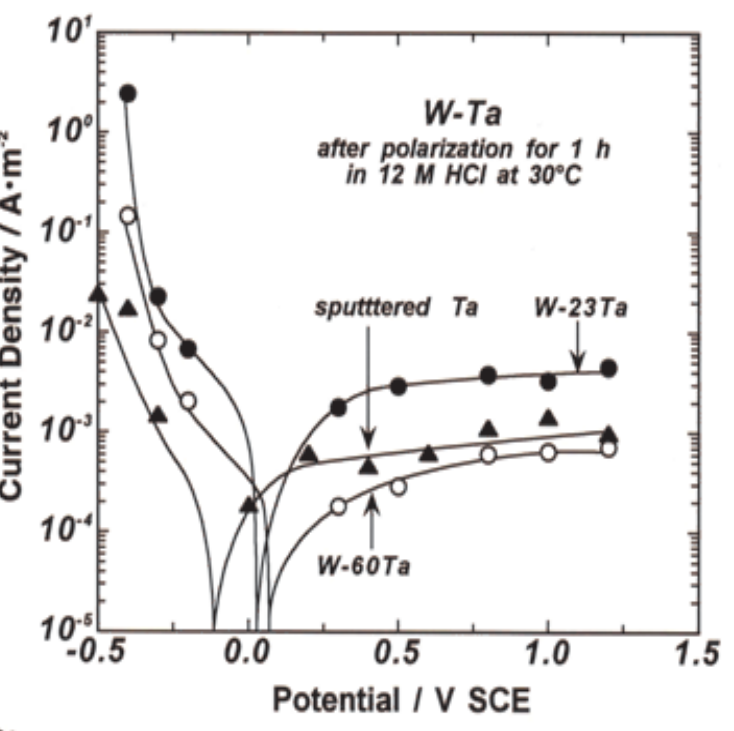

Fig.3. Potentiostatic cathodic and anodic polarization curves for the sputter-deposited W-23Ta, W-60Ta alloys including tantalum metal after potentiostatic polarization for $1 \mathrm{~h}$ in $12 \mathrm{M} \mathrm{HCl}$ solution open to air at $30^{\circ} \mathrm{C}$. 
Surface composition and passivity of W-xTa alloys The surface analyses of the anodic passive films formed on the alloys give important information for a better understanding of the synergistic effect of tungsten and tantalum in the anodic passivity of the sputter-deposited W-xTa alloys. For this purpose, the surface of the W-xTa alloys before and after immersion or potentiostatic polarization for $1 \mathrm{~h}$ in 12 $\mathrm{M} \mathrm{HCl}$ was analyzed immediately by XPS technique. XPS spectra for $\mathrm{W}-\mathrm{xTa}$ alloys over a wide binding energy region, that is, $0-1000 \mathrm{eV}$, were exhibited peaks of tungsten, tantalum, oxygen, carbon and chlorine. The C 1s spectrum [Fig. 4 (a)] arose from a contaminant hydrocarbon layer covering the specimen surface was detected at about $285 \mathrm{eV}$. For the specimen polarized or immersed in $12 \mathrm{M} \mathrm{HCl}$, the $\mathrm{Cl} 2 \mathrm{p}$ spectrum was detected at about $199 \mathrm{eV}$, which comes from chloride ions. The $\mathrm{O} 1 \mathrm{~s}$ spectrum is composed of two peaks; the lower binding energy peak at $530.2-5331.1 \mathrm{eV}$ is assigned to OM oxygen and the higher binding energy peak at 532.1-533.1 $\mathrm{eV}$ arises from $\mathrm{OH}$ oxygen (Asami 1976; Asami and Hashimoto 1977). The OM oxygen corresponds to $\mathrm{O}^{2-}$ ions in oxyhydroxide and/or oxide. The $\mathrm{OH}$ oxygen is linked to hydrogen and is composed of $\mathrm{OH}$ ions and bound water in the surface film. An example of an deconvolution of the $\mathrm{O}$ 1s spectrum measured for W-60Ta alloy is shown in Fig. 4 (b). The $\mathrm{O}^{2-}$ peak is substantially more intense than the $\mathrm{OH}$ peak in the $\mathrm{O} 1 \mathrm{~s}$ spectrum measured for the alloy after immersion for $1 \mathrm{~h}$ in $12 \mathrm{M} \mathrm{HCl}$. Accordingly, the passive films formed spontaneously on the alloy consist of oxyhydroxide in which $\mathrm{O}^{2-}$ ion is the major oxygen species.

The spectra from the alloy constituents indicated the presence of the oxidized and metallic species; the former comes from the surface film and the latter from the underlying alloy surface. The measured spectra of $\mathrm{W}$ $4 \mathrm{f}$ electrons and $\mathrm{Ta} \mathrm{4f}$ electrons were separated into $\mathrm{W}^{6+}, \mathrm{W}^{5+}, \mathrm{W}^{4+}$ and $\mathrm{W}^{\mathrm{m}}$, and $\mathrm{Ta}^{5+}$ and $\mathrm{Ta}^{\mathrm{m}}$ state spectra, respectively. The superscripts, " $6+$ ", " $5+$ ", " $4+$ "and " $\mathrm{m}$ " denote hexavalent, pentavalent, tetravalent and metallic states, respectively. The most intense peaks of the $\mathrm{W} 4 \mathrm{f}$ and $\mathrm{Ta} 4 \mathrm{f}$ spectra are located very close to each other, and the $\mathrm{Ta}^{5+} 4 \mathrm{f}_{5 / 2}$ peak and the $\mathrm{W}^{\mathrm{m}} 4 \mathrm{f}_{7 / 2}$ peak are superimposed as shown in Fig. 4 (c). On the other hand, the next intense peaks of the W $4 \mathrm{~d}$ and Ta $4 \mathrm{~d}$ electron spectra were completely overlapped each other. Therefore, the author used the W $4 \mathrm{f}$ and Ta $4 \mathrm{f}$ spectra for XPS analyses of the surface films formed on W-60Ta alloys. The standard spectra of tantalum metal, tungsten metal, pentavalent tantalum oxide and hexavalent tungsten oxide were used for the separation of metallic and oxidize states of all the measured Ta $4 \mathrm{f}$ and $\mathrm{W} 4 \mathrm{f}$ spectra, respectively. The shapes of $\mathrm{W}^{5+}$
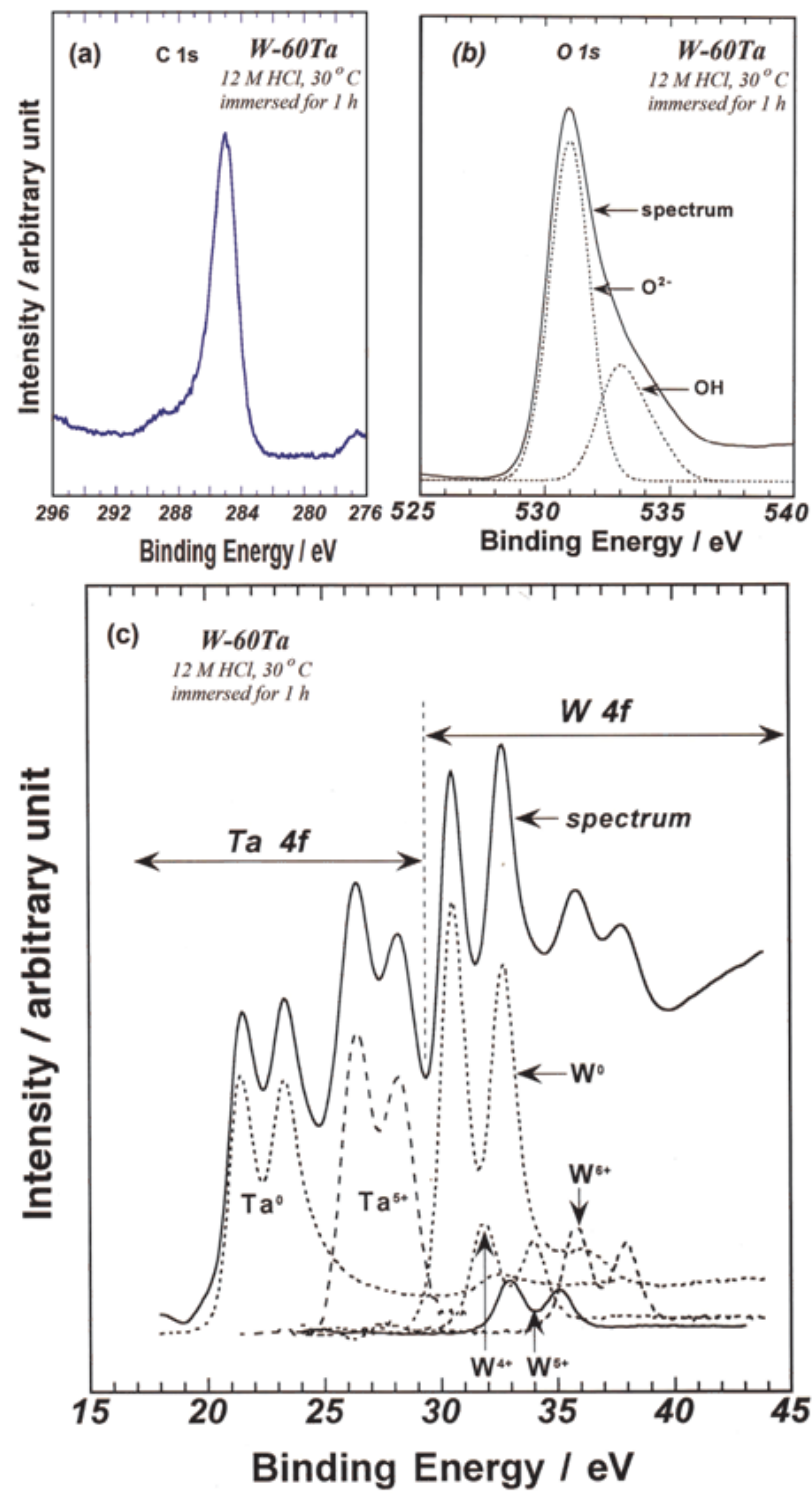

Fig.4. An example of (a) C 1s spectrum, (b) $\mathrm{O} 1 \mathrm{~s}$ spectrum and (c) the deconvolution of W $4 \mathrm{f}$ and Ta $4 \mathrm{f}$ spectra measured for the sputter-deposited W-60Ta alloy after immersion for $1 \mathrm{~h}$ in $12 \mathrm{M} \mathrm{HCl}$ solution open to air at $30^{\circ} \mathrm{C}$. 
and $\mathrm{W}^{4+}$ 4f spectra were assumed to be same as the shape of the standard $\mathrm{W}^{6+}$ spectrum. Figure 4 (c) shows an example of the deconvolution of the $\mathrm{W} 4 \mathrm{f}$ spectrum as well as the Ta $4 \mathrm{f}$ spectrum measured for the $\mathrm{W}-$ 60Ta alloy after immersion for $1 \mathrm{~h}$ in $12 \mathrm{M} \mathrm{HCl}$ at $30^{\circ} \mathrm{C}$. Four doublets of the overlapped peaks can be identified in the $\mathrm{W}$ 4f spectrum, that is, three doublets of $\mathrm{W}^{6+}$, $\mathrm{W}^{5+}$ and $\mathrm{W}^{4+}$ states and a pair of metallic state $\left(\mathrm{W}^{\mathrm{m}}\right)$. The peaks appear at about 35.7 and 37.8, 32.9 and 35.0, 31.8 and 33.9, 30.4 and $32.5 \mathrm{eV}$, respectively. The integrated intensities of these $\mathrm{W}$ 4f spectra were separately obtained by the same method as that described elsewhere (Asami 1976, Asami and Hashimoto 1977). Similarly, a pair of metallic state peaks $\left(\mathrm{Ta}^{\mathrm{m}}\right)$ at about 21.5 and $23.3 \mathrm{eV}$, and a doublet of $\mathrm{Ta}^{5+}$ state peaks at about 26.3 and $28.1 \mathrm{eV}$ can be identified in the Ta $4 \mathrm{f}$ spectrum for the W-60Ta alloy.

The changes in the surface compositions of the anodic films formed on the W-xTa alloys in $12 \mathrm{M} \mathrm{HCl}$ were analyzed by XPS. Figures 5 (a) and (b) show the changes in the cationic fractions in the surface films and the atomic fractions in the underlying alloy surface, respectively, as a function of the polarization potential. The cationic fractions in the air-formed films formed on as-polished specimens and atomic fractions in the underlying alloy surface of the as-polished specimens after mechanical polishing are also shown for comparison. Significant enrichment of tantalum in the passive films and the air-formed films with a consequent deficiency of the atomic fraction of tantalum in the underlying alloy surface is always seen. The cationic fraction of tantalum in the passive films is almost the same as the cationic composition of the air-formed film for the W-60Ta alloy, while the cationic composition of tantalum increases with potential for the W-23Ta alloy when the alloy is polarized in the transpassive potential region of tungsten [Fig. 5(a)]. On the other hand, the atomic fraction of tantalum is independent of the polarization potential in both $\mathrm{W}-$ 23Ta and W-60Ta alloys as shown in Fig. 5(b), and is almost the same as the atomic fraction for the aspolished specimens.

As mentioned above in Fig. 4(b), the passive film formed spontaneously on the $\mathrm{W}-60 \mathrm{Ta}$ alloy consists of oxyhydroxides of both cations in which $\mathrm{O}^{2-}$ ion is a major oxygen species. Figures 6 (a) and (b) show the quantitative results of the ratios of $\left[\mathrm{OH}^{-}\right] /[$cations] and $\left[\mathrm{O}^{2-}\right] /[$ cations $]$ in the anodic passive films formed on the W-23Ta and W-60Ta alloys, respectively, as a function of the polarization potential. The ratio of $\left[\mathrm{O}^{2-}\right.$ ]/[cations] is increased with increasing anodic polarization potentials, while the ratio of $\left[\mathrm{OH}^{-}\right] /$ [cations] is slightly decreased with the polarization potential in the anodic direction. These results revealed that the anodic passive films formed on the $\mathrm{W}-23 \mathrm{Ta}$ and $\mathrm{W}-60 \mathrm{Ta}$ alloys are composed of oxyhydroxides of both tungsten and tantalum cations in which $\mathrm{O}^{2-}$ ions are remarkably higher than $\mathrm{OH}^{-}$ions.
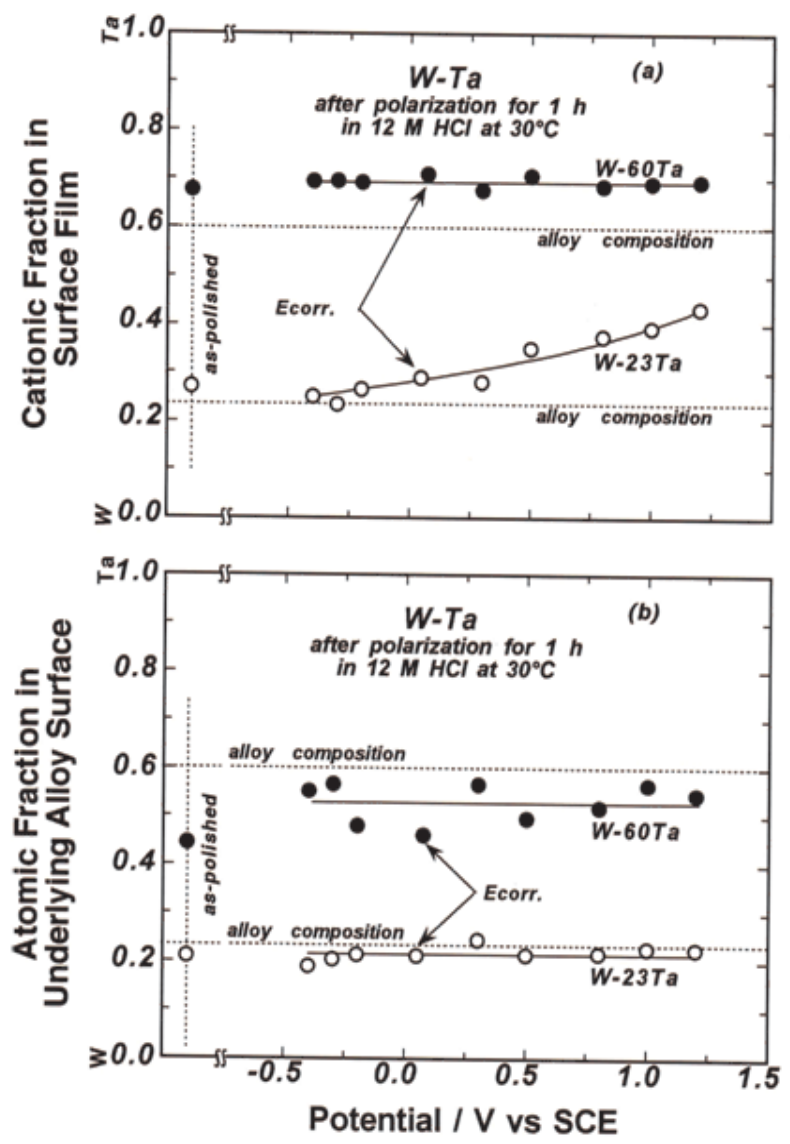

Fig.5. Changes in (a) cationic fractions in the surface films and (b) atomic fractions in the underlying alloy surface for the sputter-deposited W-23Ta and W60Ta alloys after potentiostatic polarization for $1 \mathrm{~h}$ in $12 \mathrm{M} \mathrm{HCl}$ solution open to air at $30^{\circ} \mathrm{C}$, as a function of polarization potential. 

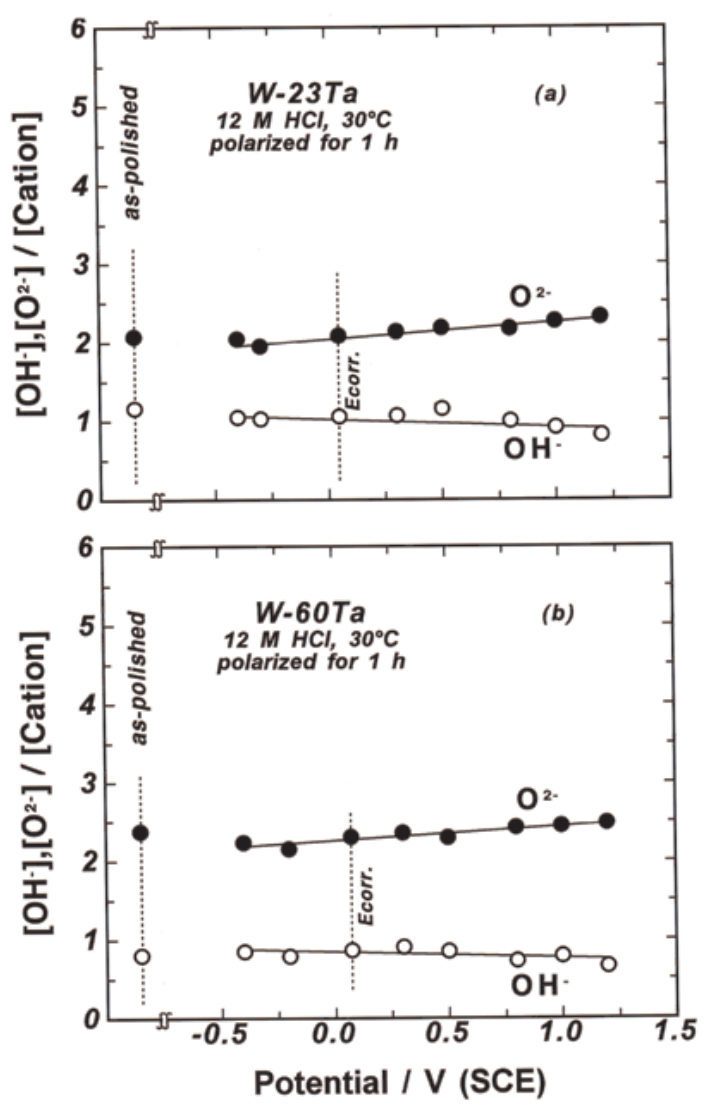

Fig.6. Changes in the ratios of $\left[\mathrm{O}^{2-}\right] /[$ cations $]$ and $\left[\mathrm{OH}^{-}\right.$ ]/[cations] in the films formed on the sputter-deposited (a) W-23Ta and (b) W-60Ta alloys after potentiostatic polarization for $1 \mathrm{~h}$ in $12 \mathrm{M} \mathrm{HCl}$ solution open to air at $30^{\circ} \mathrm{C}$, as a function of polarization potential.

\section{Anodic film thickening and distribution of tungsten ions on W-xTa alloys}

It has been reported that the anodic polarization leads to thickening of the anodic passive films for the sputter-deposited binary tungsten-based alloys in hydrochloric acid solutions (Bhattarai 1998). Remarkable anodic film thickening of the sputterdeposited tungsten-valve metal alloys was observed at $+0.2 \mathrm{~V}$ (SCE) or higher potentials. The distribution of both cations of the binary tungsten-based alloys in the anodic passive films plays important roles in the film thickening of the alloys. Similarly, the change in different oxidation states of tungsten ions in the anodic film greatly affects the film thickening. Therefore, effects of cations of alloy-constituting elements, that is, tungsten ions and $\mathrm{Ta}^{5+}$ ions, in the anodic film thickening of the binary $\mathrm{W}-\mathrm{xTa}$ alloys are discussed here in detail. Figure 7 shows the changes in the anodic film thickening of the $\mathrm{W}-\mathrm{x}$ Ta alloys after potentiostatic polarization for $1 \mathrm{~h}$ in $12 \mathrm{M} \mathrm{HCl}$ solution open to air at $30^{\circ} \mathrm{C}$, as a function of potential. The anodic polarization on the $\mathrm{W}-\mathrm{xTa}$ alloys including sputter-deposited tantalum leads to thickening of the anodic passive film. In particular, the anodic film thickening is clearly observed in the anodic potential range between 0.2 to $1.2 \mathrm{~V}$ (SCE).

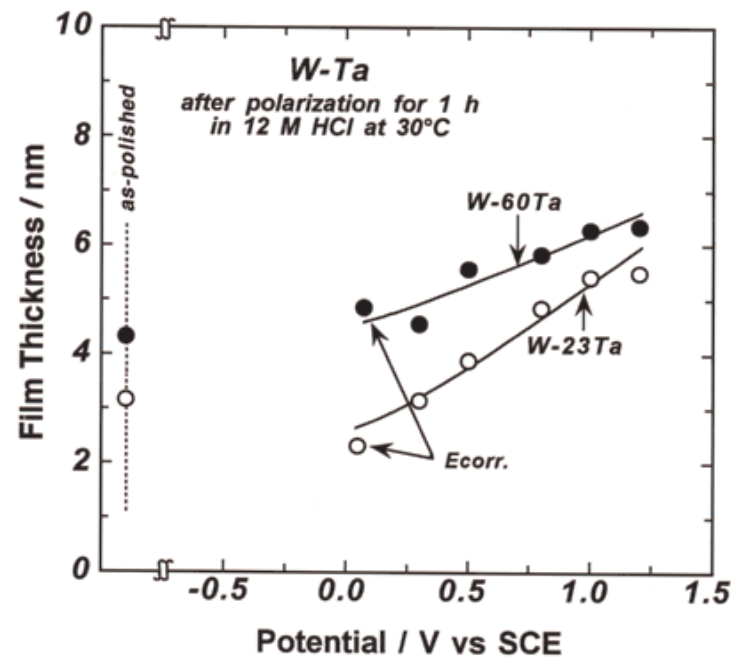

Fig.7. Changes in thicknesses of the anodic films formed on the sputter-deposited W-23Ta and W60Ta alloys including tantalum metal after potentiostatic polarization for $1 \mathrm{~h}$ in $12 \mathrm{M} \mathrm{HCl}$ solution open to air at 30C, as a function of polarization potential.

The distribution of both cations of the binary W-xTa alloys, that is, $\mathrm{W}^{\mathrm{ox}}$ and $\mathrm{Ta}^{5+}$ ions, in the anodic passivity of the alloys plays important roles in the film thickening of the alloys. Figures 8 (a) and (b) clearly show that the weights of both $\mathrm{W}^{\mathrm{ox}}$ and $\mathrm{Ta}^{5+}$ ions are increased with anodic polarization, although the cationic fractions in the surface films is almost constant particularly for $\mathrm{W}-$ 60Ta alloy as shown in Fig. 5. Similarly, the changes in different oxidation states of tungsten ion in the anodic film greatly affect the film thickening. Figure 9 (a) and (b) show the quantitative results of the change in the weights of $\mathrm{W}^{4+}, \mathrm{W}^{5+}$ and $\mathrm{W}^{6+}$ ions in the films formed on $\mathrm{W}-23 \mathrm{Ta}$ and W-60Ta alloys, respectively. The $\mathrm{W}^{6+}$ ion increases with decreasing of $\mathrm{W}^{4+}$ and $\mathrm{W}^{5+}$ ions with anodic polarization for $1 \mathrm{~h}$ in $12 \mathrm{M} \mathrm{HCl}$ at $30^{\circ} \mathrm{C}$. These results revealed that both cations of the $\mathrm{W}$-Ta alloys contribute for the anodic film thickening. The main contribution among tungsten ions for the anodic film thickening of 
the $\mathrm{W}-\mathrm{Ta}$ alloys is $\mathrm{W}^{6+}$ ions, because a relatively stable and sparingly soluble $\mathrm{W}^{6+}$ ions increase remarkably in the anodic passive film in the potential region where film thickening is remarkable in $12 \mathrm{M} \mathrm{HCl}$ solution. Consequently, anodic polarization results in the anodic film thickening due to increase in $\mathrm{W}^{6+}$ and $\mathrm{Ta}^{5+}$ ions.

In conclusion, a beneficial effect of tungsten and tantalum in the passivity of the anodic passive films formed on the sputter-deposited binary W-xTa alloys is studied using electrochemical measurements and XPS analysis. The quantitative surface analyses by XPS are clarified that the improved anodic passivity of the alloys than those of alloy-constituting elements is based on the formation of new anodic passive oxyhydroxide films composed of $\mathrm{W}^{6+}$ and $\mathrm{Ta}^{5+}$ ions. These films have higher protectiveness and stability than those of passive oxyhydroxide films of alloyconstituting elements, that is, oxyhydroxides of hexavalent tungsten and pentavalent tantalum after potentiostatic polarization for $1 \mathrm{~h}$ in $12 \mathrm{M} \mathrm{HCl}$ solution open to air at $30^{\circ} \mathrm{C}$.
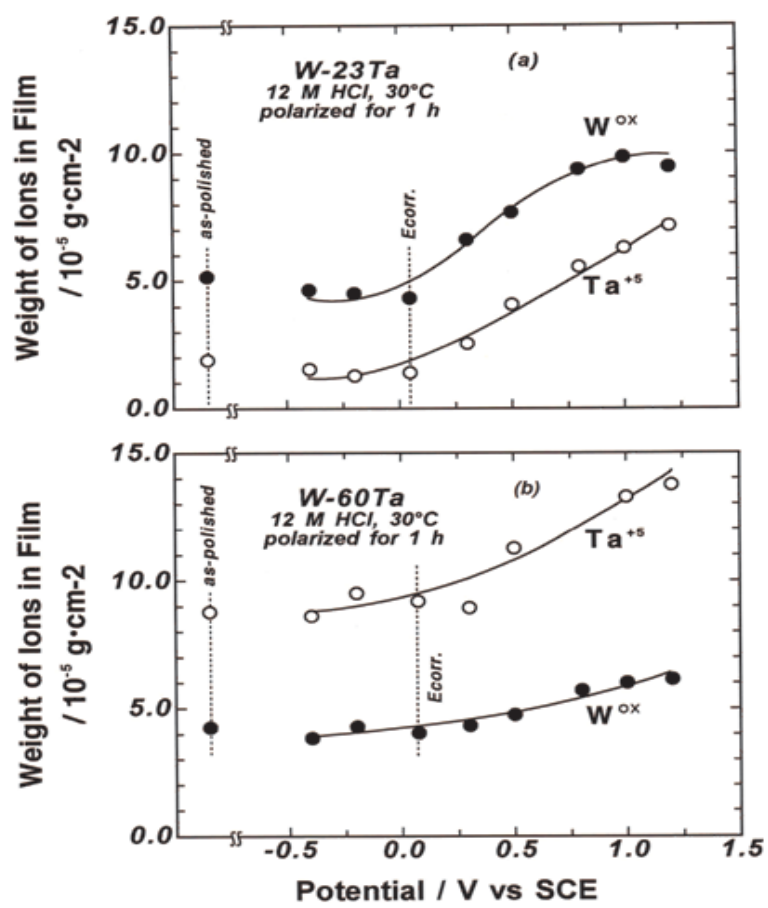

Fig.8. Changes in weights of cations in the surface films formed on the sputter-deposited (a) W-23Ta and (b) W-60Ta alloys after potentiostatic polarization for $1 \mathrm{~h}$ in $12 \mathrm{M} \mathrm{HCl}$ solution open to air at $30^{\circ} \mathrm{C}$, as a function of polarization potential.
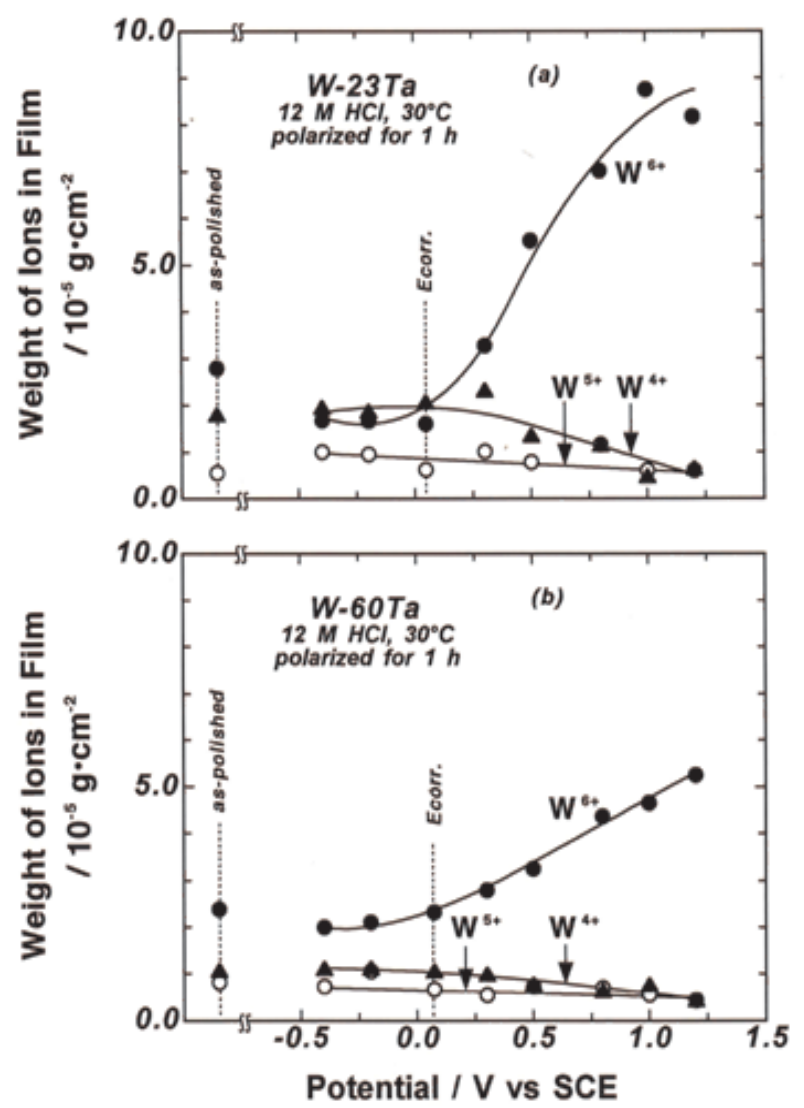

Fig.9. Changes in weights of $\mathrm{W}^{4+}, \mathrm{W}^{5+}$ and $\mathrm{W}^{6+}$ ions in the surface films formed on the sputter-deposited (a) W-23Ta and (b) W-60Ta alloys after potentiostatic polarization for $1 \mathrm{~h}$ in $12 \mathrm{M} \mathrm{HCl}$ solution open to air at $30^{\circ} \mathrm{C}$, as a function of polarization potential.

\section{Acknowledgements}

Author would like to express his sincere gratitude to Professor Emeritus; Dr. K. Hashimoto, Dr. K. Asami and Dr. A. Kawashima of IMR of Tohoku University, Sendai and Professor Dr. H. Habazaki of Hokkaido University for their kind help and discussions on the XPS analysis. Author is thankful to Japan Government and Diaki Ataka Engineering Co. Ltd. for providing an opportunity to visit Tohoku Institute of Technology, Japan as a Research Fellow.

\section{References}

Asami, K. 1976. A precisely consistent energy calibration method for X-ray photoelectron spectroscopy. Journal of Electron Spectroscopy and Related Phenomena 9:469-478. 
Jagadeesh Bhattarai/X-ray Photoelectron.......

Asami, K. and K. Hashimoto. 1977. The X-ray photoelectron spectra of several oxides of iron and chromium. Corrosion Science 17:559"570.

Bhattarai, J. 1995. Corrosion behavior of sputter-deposited tungsten-base alloys. Research Reports, Institute for Materials Research (IMR), Tohoku University, Sendai, Japan, 43+IV pp.

Bhattarai, J. 1998. Tailoring of corrosion resistance tungsten alloys by sputtering. Ph. D. thesis, Department of Materials Science, Tohoku University, Japan. 229 pp.

Bhattarai, J. 2010. X-ray photoelectron spectroscopic analyses on the corrosion-resistant $\mathrm{W}-\mathrm{Cr}-\mathrm{Ni}$ alloys in $12 \mathrm{M} \mathrm{HCl}$. Transactions of the Materials Research Society of Japan 35 (1):1-6.

Bhattarai, J. 2011 a. The corrosion behavior of sputterdeposited ternary W-Zr-(1518)Cr alloys in $12 \mathrm{M} \mathrm{HCl}$. African Journal of Pure and Applied Chemistry 5 (8):212-218.

Bhattarai, J. 2011 b. X-ray photoelectron spectroscopic study on the anodic passivity of sputter-deposited $\mathrm{W}-\mathrm{Nb}$ alloys $12 \mathrm{M} \mathrm{HCl}$ solution. Journal of Scientific Research 3(3):457"470.

Bhattarai, J., E. Akiyama, A. Kawashima, K. Asami and K. Hashimoto. 1995. The corrosion behavior of sputterdeposited amorphous W-Ti alloys in $6 \mathrm{M} \mathrm{HCl}$ solution. Corrosion Science 37:2071"2086.

Bhattarai, J., E. Akiyama, H. Habazaki, A. Kawashima, K. Asami and K. Hashimoto. 1997. Electrochemical and XPS studies of the corrosion behavior of sputterdeposited amorphous $\mathrm{W}-\mathrm{Zr}$ alloys in 6 and $12 \mathrm{M} \mathrm{HCl}$ solutions. Corrosion Science 39:355-375.

Bhattarai, J., E. Akiyama, H. Habazaki, A. Kawashima, K. Asami and K. Hashimoto. 1998 a. The passivation behavior of sputter-deposited amorphous W-Ta alloys in $12 \mathrm{M} \mathrm{HCl}$ solution. Corrosion Science 40:757-779.

Bhattarai, J., E. Akiyama, H. Habazaki, A. Kawashima, K. Asami and K. Hashimoto. 1998 b. Electrochemical and XPS studies of the corrosion behavior of sputterdeposited amorphous $\mathrm{W}-\mathrm{Nb}$ alloys in concentrated hydrochloric acid solutions. Corrosion Science 40:19"42.

Bhattarai, J., E. Akiyama, H. Habazaki, A. Kawashima, K. Asami and K. Hashimoto. 1998 c. Electrochemical and XPS studies of the passivation behavior of sputter" deposited $\mathrm{W}-\mathrm{Cr}$ alloys in $12 \mathrm{M} \mathrm{HCl}$ solution. Corrosion Science 40:155-175.

Bui, N., A. Irhzo, F. Dabosi, Y. Limouzin-Maire. 1983. On the mechanism of improved passivation by addition of tungsten to austenitic stainless steels. Corrosion 39:491-496.

Di Quarto, F., S. Piazza and C. Sunseri. 1983. Passivity of Metals and Semiconductors. Proceedings of $5^{\text {th }}$ International Symposium on Passivity (ed. M. Froment). The Societe de Chimie Physique, Bombanners, France. 497 pp.
El-Moneim, A. A., E. Akiyama, H. Habazaki, A. Kawashima, K. Asami and K. Hashimoto. 1997. The corrosion behavior of sputter-deposited amorphous $\mathrm{Mn}-\mathrm{Ta}$ alloys in $0.5 \mathrm{M} \mathrm{NaCl}$ solution. Corrosion Science 39:1965-1979.

Habazaki, H., A. Kawashima, K. Asami and K. Hashimoto. 1991 a. in Proceeding of the Symposium on the Application of Surface Analysis Methods to Environment/ Material Interactions (eds. D. R. Baer, C. R. Clayton and G. D. Davis).The Electrochemical Society, Inc., Pennington, USA. 467 pp.

Habazaki, H., A. Kawashima, K. Asami and K. Hashimoto. $1991 \mathrm{~b}$. The effect of tungsten on the corrosion behavior of amorphous $\mathrm{Fe}-\mathrm{Cr}-\mathrm{W}-\mathrm{P}-\mathrm{C}$ alloys in $1 \mathrm{M} \mathrm{HCl}$. Journal of Electrochemical Society 138:76-81.

Habazaki, H., A. Kawashima, K. Asami and K. Hashimoto. 1992. The corrosion behavior of amorphous $\mathrm{Fe}-\mathrm{Cr}-\mathrm{Mo}-\mathrm{P}-\mathrm{C}$ and $\mathrm{Fe}-\mathrm{Cr}-\mathrm{W}-\mathrm{P}-\mathrm{C}$ alloys in $6 \mathrm{M} \mathrm{HCl}$ solution. Corrosion Science 33:225-232.

Hashimoto, K. 1993. Chemical properties of rapidly solidified alloys. in Rapidly Solidified Alloys; Processes, Structures, Properties, Applications (ed. Howard H. Liebermann), Marcel Dekker Inc., New York. 591-615.

Hashimoto, K. 2007. The role of corrosion-resistant alloying elements in passivity. Corrosion Science 49: $42-52$.

Hashimoto, K., H. Habazaki, E. Akiyama, H. Yoshioka, J. H. Kim, P. Y. Park, A. Kawashima and K. Asami. 1996. Recent progress in corrosionresistant new alloys prepared by sputter deposition. The Science Reports of the Research Institutes Tohoku University A42:99-105.

Johnson, J. W. and C. L. Wu. 1971. Journal of Electrochemical Society 118:1909.

Kawashima, A., K. Shimamura, S. Chiba, T. Masunaga, K. Asami and K. Hashimoto. 1985. in Proc. $4^{\text {th }}$ AsianPacific Corrosion Control Conference, Tokyo. Vol. 2:1042 pp.

Kawashima, A., K. Asami and K. Hashimoto. 1994. Corrosion Science 24:807-812.

Kim, J. H., E. Akiyama, H. Habazaki, A. Kawashima, K. Asami and K. Hashimoto. 1994. An XPS study of the corrosion behavior of sputter-deposited amorphous $\mathrm{Cr}-\mathrm{Nb}$ and $\mathrm{Cr}-\mathrm{Ta}$ alloys in $12 \mathrm{M} \mathrm{HCl}$ solution. Corrosion Science 36:511-523.

Lee, H.-J., E. Akiyama, H. Habazaki, A. Kawashima, K. Asami and K. Hashimoto. 1996. The corrosion behavior of amorphous and crystalline $\mathrm{Ni}-10 \mathrm{Ta}-20 \mathrm{P}$ alloys in $12 \mathrm{M} \mathrm{HCl}$. Corrosion Science 38:1269-1279.

Lee, H.-J., E. Akiyama, H. Habazaki, A. Kawashima, K. Asami and K. Hashimoto. 1997. The roles of tantalum and phosphorus in the corrosion behavior of $\mathrm{Ni}-\mathrm{Ta}-\mathrm{P}$ alloys in $12 \mathrm{M} \mathrm{HCl}$. Corrosion Science 39:321-332. 
Naka, M., K. Hashimoto and T. Masumoto. 1978. High corrosion resistance of amorphous $\mathrm{Fe}-\mathrm{Mo}$ and $\mathrm{FeW}$ alloys in HCl. Journal of Non-Crystalline Solids 29:61-65.

Park, P.Y., E. Akiyama, A. Kawashima, K. Asami and K. Hashimoto. 1996. The corrosion behavior of sputterdeposited Mo-Ta alloys in $12 \mathrm{M} \mathrm{HCl}$ solution. Corrosion Science 38: 397-411.

Shaw, B. A., T. L. Fritz, G. D. Davis and W. C. Moshier. 1991. The influence of tungsten additions on the passivity of aluminum. Journal of Electrochemical Society 138:3288-3295.
Wang, R. and M. D. Merz. 1984. Corrosion resistance of amorphous FeNiCrW alloys. Corrosion Science 40:272-280.

Yoshioka, H., A. Kawashima, K. Asami and K. Hashimoto. 1991. An XPS study of the corrosion behavior of sputter-deposited amorphous $\mathrm{Al}-\mathrm{W}$ alloys in $1 \mathrm{M} \mathrm{HCl}$. Corrosion Science 32:313-325.

Yoshioka, H., H. Habazaki, A. Kawashima, K. Asami and K. Hashimoto. 1993. Corrosion, Electrochemistry and Catalysis of Metastable Metals and Intermetallics (eds C. R. Clayton and K. Hashimoto). The Electrochemical Society, 72 pp. 